Article

\title{
Electrospun PAN/MAPbI 3 Composite Fibers for Flexible and Broadband Photodetectors
}

\author{
Gaolin Li, Zhenhua Jiang *, Weilin Wang, Zengyong Chu *, Ye Zhang and Chunhua Wang \\ College of Liberal Arts and Sciences, National University of Defense Technology, Changsha 410073, China; \\ ligaolin12@nudt.edu.cn (G.L.); wangweilin0930@hotmail.com (W.W.); zhangye8905@foxmail.com (Y.Z.); \\ w_chunhua@tom.com (C.W.) \\ * Correspondence: jiangzhenhua@nudt.edu.cn (Z.J.); chuzy@nudt.edu.cn (Z.C.); Tel.: +86-731-87001823 (Z.C.)
}

Received: 10 December 2018; Accepted: 26 December 2018; Published: 2 January 2019

\begin{abstract}
Methylammonium lead triiodide perovskite $\left(\mathrm{CH}_{3} \mathrm{NH}_{3} \mathrm{PbI}_{3}, \mathrm{MAPbI}_{3}\right)$ has been emerging as an easy processing and benign defect material for optoelectronic devices. Fiber-like perovskite materials are especially in demand for flexible applications. Here we report on a kind of polyacrylonitrile (PAN)/ $\mathrm{MAPbI}_{3}$ composite fiber, which was electrospun from the mixing solution of $\mathrm{PAN}$ and $\mathrm{MAPbI}_{3}$. The absorption edge and optical gap of the $\mathrm{PAN} / \mathrm{MAPbI}_{3}$ composite fibers can be easily tuned as the ratio of the perovskite changes. Both the moisture stability and the thermal stability of the perovskite are improved with the protection of PAN polymers. Flexible photodetectors based on this perovskite fiber were fabricated and analyzed. The photoresponse of the detector was highly sensitive to broadband visible light, and reached $6.5 \mu \mathrm{A} \mathrm{W}^{-1}$ at $700 \mathrm{~nm}$ with a voltage bias of $10 \mathrm{~V}$. Compared with pure $\mathrm{MAPbI}_{3}$ photodetectors, this composite fiber photodetector has much-improved stability and flexibility, which can even be used to detect motion-related angular changes.
\end{abstract}

Keywords: perovskite fiber; electrospinning; photodetector; polyacrylonitrile

\section{Introduction}

As a new photovoltaic material, methylammonium lead triiodide perovskite $\left(\mathrm{CH}_{3} \mathrm{NH}_{3} \mathrm{PbI}_{3}\right.$, denoted as $\mathrm{MAPbI}_{3}$ ) has a low bandgap, a large absorption coefficient, a high carrier mobility, a long carrier diffusion length, and a low-cost synthetic route [1-6]. These photoelectric devices, based on organolead halide thin films, are mostly cast from nanocrystals or micro-size grains [7-10]. Moreover, as a low-dimensional material, pure perovskite fiber has an extremely low defect density, similar to its single crystal counterpart [11-14], which gives it many potential applications in solar cells, photodetectors, transistors, light-emitting diodes, and so on $[15,16]$. One-dimensional perovskite fiber is also promising in improving carriers transfer and reducing the recombination of the electron-hole pairs $[17,18]$. However, the concomitant disadvantage of optoelectronic devices imbedded with fibers is their large surface-area-to-volume ratio $[19,20]$, which usually catalyzes the decomposition of perovskite when exposed to moisture and light, thus degrading the device stability [20-22]. As a result, many of these $\mathrm{MAPbI}_{3}$ fiber-based photoelectric devices are not satisfactory in performance and stability. Therefore, it was urgent to develop a facile method to prepare $\mathrm{MAPbI}_{3}$ fibers with excellent optical trapping and good stability.

Electrospinning is a simple fabrication approach for low-dimensional nanomaterials [23-25]. The first patent on electrospinning was reported in the 1930s. From then on, great progress and applications have been made [26,27]. It is simple and convenient for the synthesis of continuous polymeric fibers, and thus also promising for the fabrication of perovskite fibers.

Polyacrylonitrile (PAN) can be co-dissolved with $\mathrm{MAPbI}_{3}$ in $N, N$-Dimethylformamide solvents, so we chose the composite solution of PAN and MAPbI3 for electrospinning. By performing polymer 
electrospinning of polyacrylonitrile (PAN) and $\mathrm{MAPbI}_{3}$, we successfully synthesized $\mathrm{PAN} / \mathrm{MAPbI}_{3}$ composite fibers. The obtained fibers exhibit excellent photoelectric and mechanical properties for flexible devices. Photodetectors based on the composite fibers were also constructed and analyzed. These photodetectors exhibit impressive stability and flexible photoresponse under various situations. To our knowledge, this is the first report on perovskite photodetectors based on electrospun $\mathrm{PAN} / \mathrm{MAPbI}_{3}$ composite fibers. Our work explores a new way towards synthesis of various perovskite/polymer composite materials well-suited for optoelectronic devices with much improved stability.

\section{Materials and Methods}

\subsection{Synthesis of PAN/MAPbI 3 Composite Fibers}

Chemical grade methyl ammonium iodide $\left(\mathrm{CH}_{3} \mathrm{NH}_{3} \mathrm{I}\right)$, lead iodide $\left(\mathrm{PbI}_{2}\right)$, and $\mathrm{N}, \mathrm{N}$-Dimethylformamide (DMF) were purchased from Xi'an Polymer Light Technology Corp (Xi'an, China). Polyacrylonitrile (PAN) was obtained from Jilin Carbon Fiber Ltd (Jilin, China). All the materials were used as received. The $\mathrm{MAPbI}_{3}$ precursor solution was synthesized by mixing $\mathrm{CH}_{3} \mathrm{NH}_{3} \mathrm{I}$ and $\mathrm{PbI}_{2}$ at a 1:1 molar ratio in DMF and stirring for $2 \mathrm{~h}$ at $60{ }^{\circ} \mathrm{C}$. The obtained $\mathrm{MAPbI}_{3}$ solution is denoted as solution A $\left(2.35 \mathrm{~mol} / \mathrm{L}\right.$ for $\left.\mathrm{MAPbI}_{3}\right)$. The PAN precursor solution was prepared by dissolving polyacrylonitrile in DMF and stirring for $24 \mathrm{~h}$ at room temperature. The obtained PAN solution is denoted as solution B (15 wt $\%$ for PAN). The PAN/MAPbI 3 composite solution was prepared by mixing solutions A and B and stirring for $2 \mathrm{~h}$. Here, solution A was added to solution B to make the final mass fraction of PAN change from $15 \mathrm{wt} \%$ to $10 \mathrm{wt} \%, 8 \mathrm{wt} \%$, and $6 \mathrm{wt} \%$.

The electrospinning setup is shown in Figure 1, which includes a plastic syringe, an aluminum foil, and DC power. The syringe, with a metallic needle tip, was loaded with the composite precursor solution. The needle tip was connected to the positive electrode $(15 \mathrm{kV})$, and the aluminum foil was connected to the negative electrode. The flow rate was fixed as $1.5 \mathrm{~mL} / \mathrm{h}$, and the distance from the needle tip-end to the collector was fixed as $15 \mathrm{~cm}$. The composite fibers deposited on the aluminum foil and formed film under the action of high voltage. Finally, the as-synthesized composite fibers in the film state were dried in an air oven at $65^{\circ} \mathrm{C}$ for at least $3 \mathrm{~h}$ for removal of the solvent.

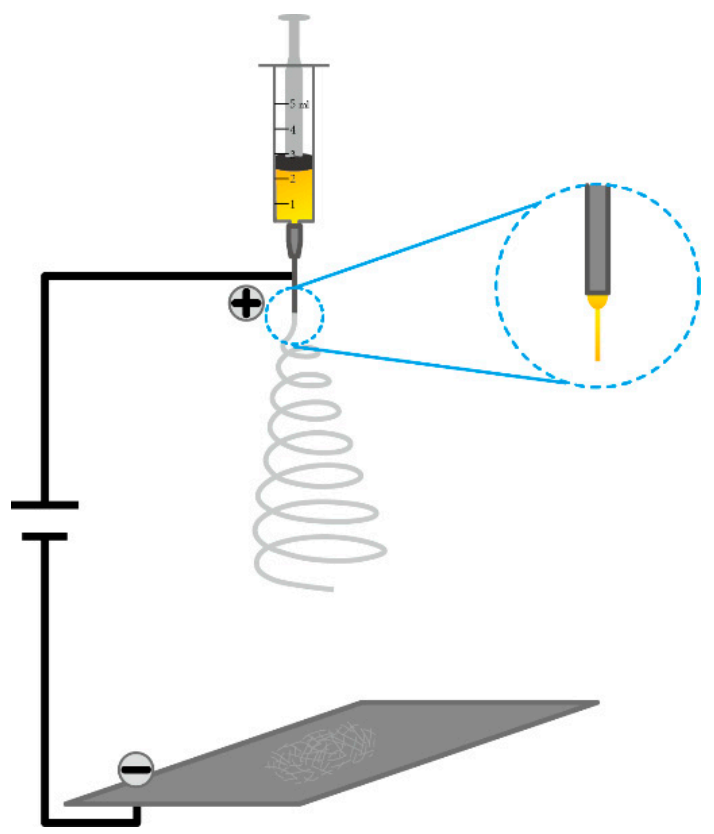

Figure 1. Schematic diagram of the electrospinning setup. 
The $\mathrm{MAPbI}_{3}$ contents of the composite fibers prepared from the $10 \mathrm{wt} \%, 8 \mathrm{wt} \%$, and $6 \mathrm{wt} \%$ solutions were $85.7 \mathrm{wt} \%, 77.7 \mathrm{wt} \%$, and $66.6 \mathrm{wt} \%$ respectively, so the composite fibers were named as M85.7, M77.7, and M66.6, respectively.

\subsection{Characterization of $\mathrm{PAN} / \mathrm{MAPbI}{ }_{3}$ Composite Fibers}

The surface morphologies of the composite fibers were characterized using a S-4800 scanning electron microscope (SEM) (Hitachi, East Coast Harbor, Honshu Island, Japan). Crystal structures were analyzed with X-ray powder diffraction (XRD), using a Bruker D8ADVANCE diffractometer (Bruker, Karlsruhe, Germany) with $\mathrm{Cu}-\mathrm{K} \alpha$ radiation $(\lambda=1.54178 \AA$ ). The crystal distributions of the composite fibers were characterized using a Joel-2100F transmission electron microscope (TEM) (JEOL Ltd., Tokyo, Japan). The ultra-violet-near infra-red (UV-Vis-NIR) diffused reflectance spectrum (DRS) was recorded on a HITACHI U-4100 UV/Vis-NIR spectrophotometer (Hitachi, East Coast Harbor, Honshu Island, Japan). The photoluminescence (PL) spectra were recorded on a HITACHI F-4600 fluorescence spectrofluorometer (Hitachi, East Coast Harbor, Honshu Island, Japan). Thermogravimetric analysis (TGA) was performed using a PerkinElmer STA-6000 thermogravimetric analyzer (PerkinElmer, Waltham, MA, USA).

\subsection{Fabrication of PAN/MAPbI $\mathrm{I}_{3}$ Composite Fiber Photodetectors}

The photodetector was fabricated in a vertical stack way. From the bottom to the top, the layers were: Glass, $\mathrm{PAN} / \mathrm{MAPbI}_{3}$ composite fiber film, interdigitated copper electrodes, and glass. The electrodes contacted tightly with the composite fiber film so as to minimize the contact resistance. Notably, the effective area of the photodetectors was as large as $2.40 \mathrm{~cm}^{2}$, which is at least one order of magnitude larger than those of other reported perovskite-based photodetectors. Large-area devices have more advantages for practical applications. Flexible photodetectors were constructed through replacing glass substrate with flexible polyethylene terephthalate (PET), which was then coated with silver electrodes. To ensure the accuracy of the results, we assembled five photodetectors for each experiment and carried out photoresponse measurements at least three times for each photodetector. The photoresponses of the photodetectors in this work are the average value of the measurements, which is in a small spread $(<0.05 \mu \mathrm{A})$.

\subsection{Photoresponse Measurements}

Photoelectronic measurements of the obtained photodetectors were performed in a three electrodes system on an electrochemical workstation (CHI760E). The incident power light was measured by a photoradiometer (PL-MW2000) (PerfectLight, Beijing, China). Different wavelength (420 to $700 \mathrm{~nm}$ ) lights from a PerfectLight PLS-SXE300/300UV Xenon lamp (PerfectLight, Beijing, China) were focused through filters (Figure S3). Photoelectronic measurements were performed in air and at room temperature without any encapsulation.

\section{Results and Discussion}

\subsection{Microstructures of the Composite Fibers}

The PAN $/ \mathrm{MAPbI}_{3}$ composite fibers were electrospun from PAN solutions using a setup shown in Figure 1. The fibers were deposited on an aluminum foil in the form of a network film (Figure 2a). Surface morphologies of the composite fibers were characterized using SEM, as shown in Figure $2 b-f$. The fibers were randomly arranged in nonwoven states. With increases in the content of $\mathrm{MAPbI}_{3}$ (e.g., from M66.6 to M85.7), the surfaces of the PAN/MAPbI 3 composite fibers became rougher, and even rougher than pure PAN fibers (Figure S1). The average diameter of the $\mathrm{PAN} / \mathrm{MAPbI}_{3}$ composite fibers was about 1-2 $\mu \mathrm{m}$, and seemed to increase with increasing $\mathrm{MAPbI}_{3}$ content (Figure 3). 

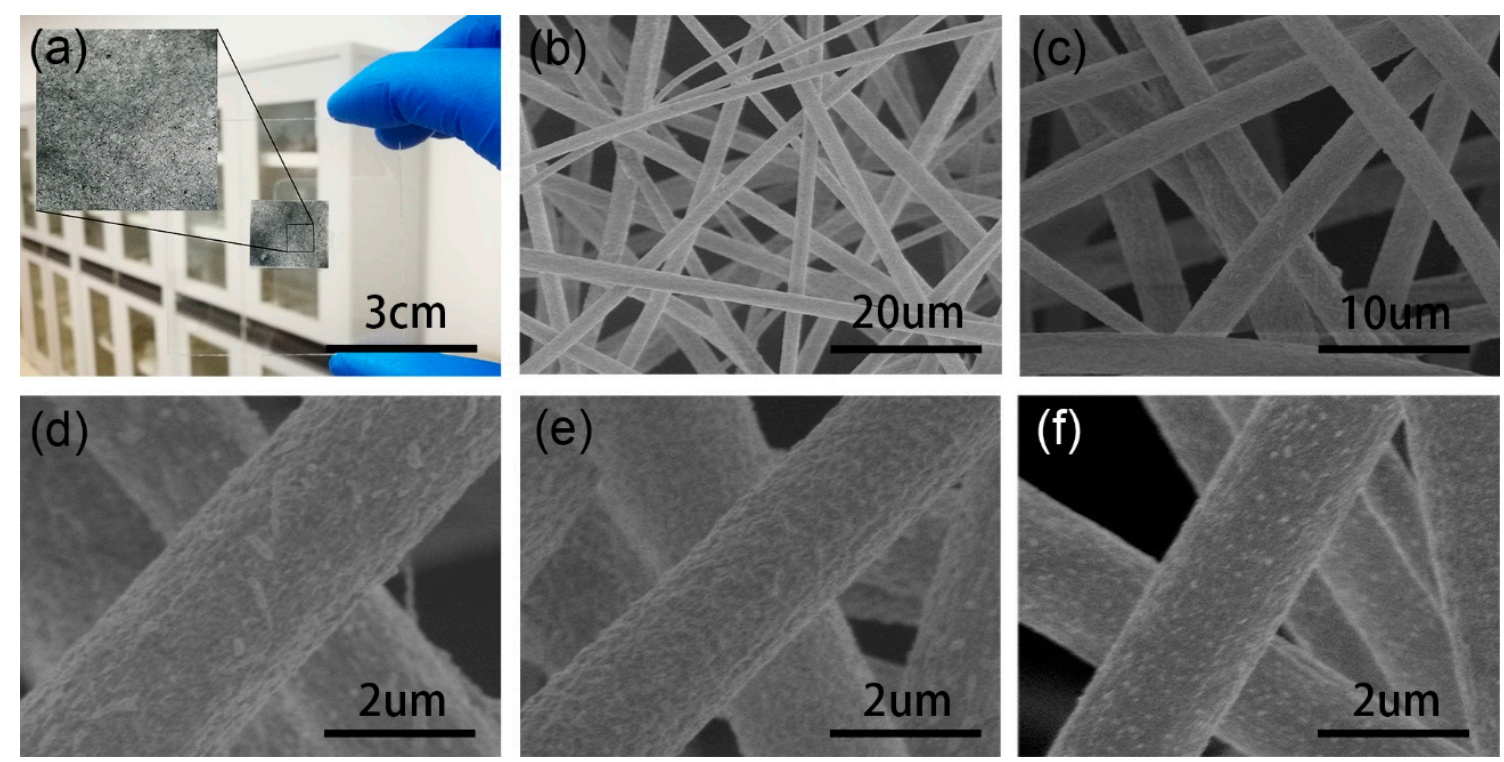

Figure 2. Optical and SEM images of the composite fibers. (a) Optical image of the composite fibers. (b-f) SEM images of the composite fibers: (b-d) M85.7, (e) M77.7, and (f) M66.6.

(a)

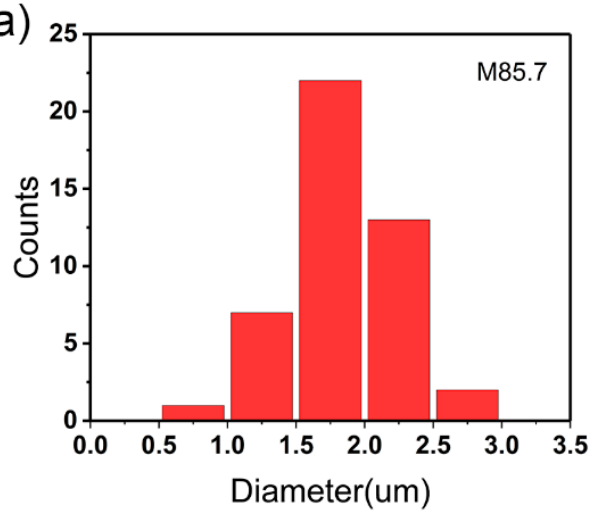

(c)

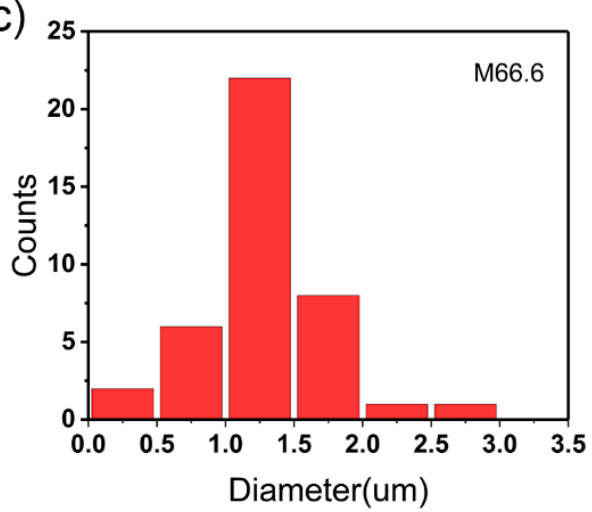

(b)

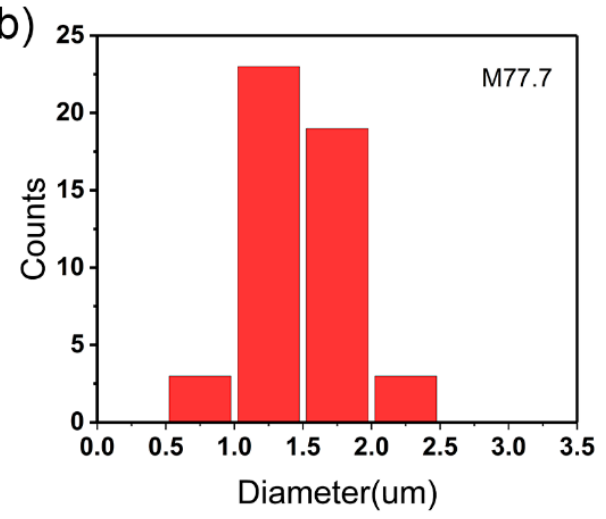

(d)

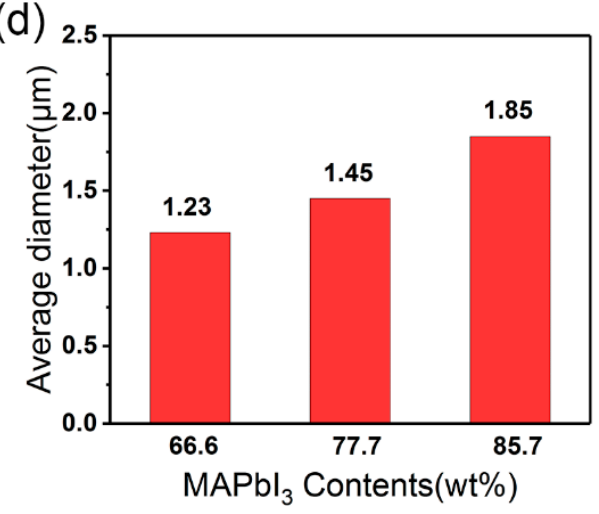

Figure 3. Diameter distributions of the composite fibers. (a) M85.7, (b) M77.7, and (c) M66.6. (d) Relationship between the average diameter and $\mathrm{MAPbI}_{3}$ content.

Corresponding X-ray diffractions of the $\mathrm{MAPbI}_{3}$ crystals imbedded in the composite fibers are shown in Figure 4a. The XRD patterns from the reference crystals prepared by bottom seeded solution growth (BSSG) match well with those of the composite fibers. It is noticed that there are some differences in the peak quantity of the composite fibers and pure $\mathrm{MAPbI}_{3}$ powders. The composite fibers have several new peaks at $12.95^{\circ}, 22.19^{\circ}$, and $26.25^{\circ}$, which may correspond to the reflections from the PAN [28]. The XRD results reveal that the synthetic composite fibers are consisting of PAN 
and the pure phase of $\mathrm{MAPbI}_{3}$ with good crystallinity. It is also found that the peak intensities of the composite fibers become stronger with increases in the content of $\mathrm{MAPbI}_{3}$. In order to observe the crystal distribution of the composite fibers, composite fibers were grinded and characterized using TEM. As shown in Figure $4 b, c$, nanocrystals imbedded in the fibers were evenly distributed, which is in agreement with cross-sectional SEM images of the composite fibers (Figure S2).

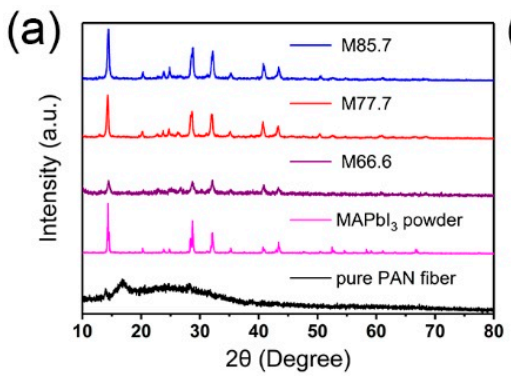

(b)

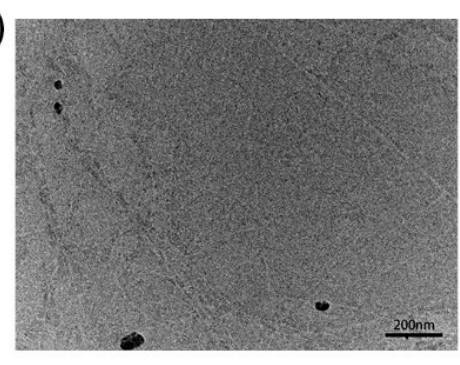

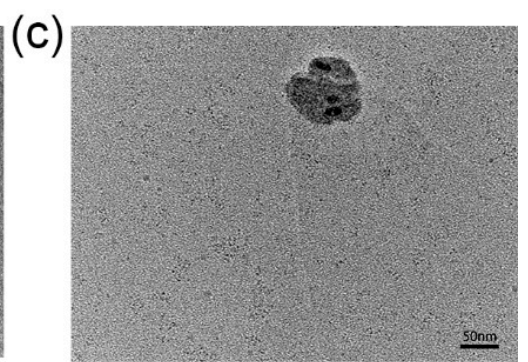

Figure 4. XRD and TEM profiles of the composite fibers. (a) XRD of the composite fibers, $\mathrm{MAPbI}_{3}$ powder and pure polyacrylonitrile (PAN), and (b,c) TEM images of the composite fibers.

\subsection{Optical Property of the Composite Fibers}

Figure 5 a depicts the DRS spectra of pure $\mathrm{MAPbI}_{3}$ perovskite powders, $\mathrm{PAN} / \mathrm{MAPbI}$ composite fibers, and pure PAN fibers. The white PAN fibers are reflective to visible light, while the PAN/MAPbI perovskite fibers have a broadband absorption of visible light due to the incorporation of black $\mathrm{MAPbI}_{3}$ perovskite nanocrystals. All the reflection spectra of the composite fibers have a clear band edge cutoff, which corresponds to the typical semiconductor absorption. With the increase of perovskite content, there is a red-shift of the band edge cutoff, which gets closer to that of the pure $\mathrm{MAPbI}_{3}$ powder. Further analysis was carried out using the transformed Kubelka-Munk method with the UV-vis-NIR DRS data, which suggested that the intrinsic bandgap is $1.460 \mathrm{eV}$ for pure $\mathrm{MAPbI}_{3}$ perovskite powder, as shown in Figure 5b. The bandgap of composite fibers is about $1.530 \mathrm{eV}$, which is approximately 60-80 meV shifted toward the higher energy side.
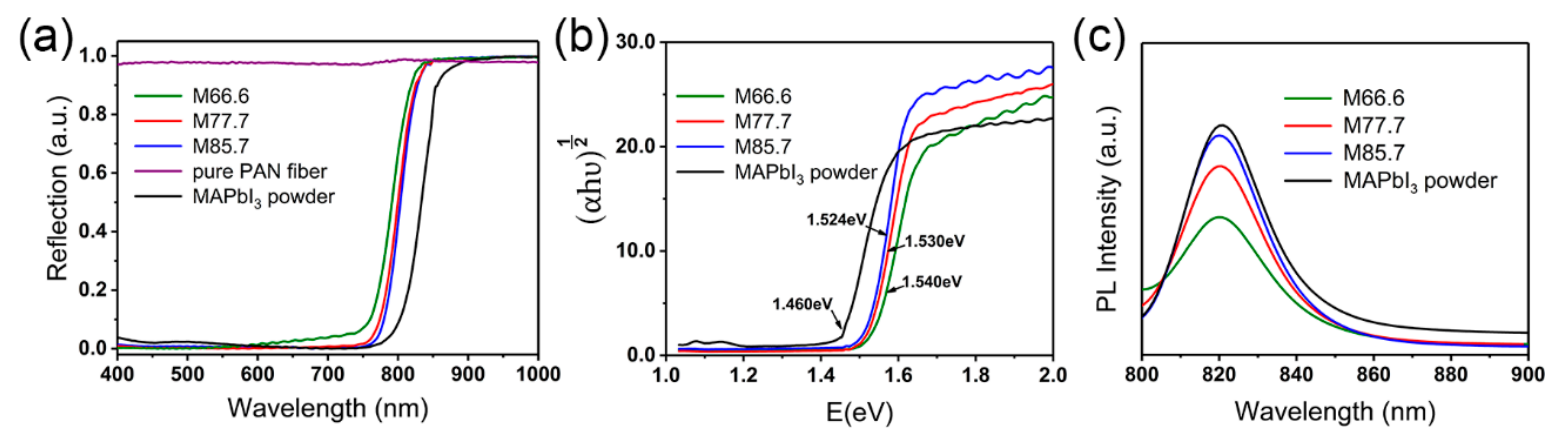

Figure 5. Optical properties of the composite fibers, $\mathrm{MAPbI}_{3}$ powder, and pure PAN fibers.

(a) UV-Vis-NIR diffused reflectance spectrum (DRS), (b) bandgap, and (c) photoluminescence spectra.

Figure $5 c$ shows the PL spectra of the composite fibers and the pure $\mathrm{MAPbI}_{3}$ perovskite powders. Composite fibers and the pure $\mathrm{MAPbI}_{3}$ perovskite powders exhibit obvious PL signals, with similar curve shapes mainly located in the near-infrared region. Slight red-shifting of the PL peaks was observed for the composite fibers with the increase of $\mathrm{MAPbI}_{3}$ content, which is in accordance with their narrower band gap.

Obviously, the apparent optical band gap of the composite fibers can be slightly tuned by changing the blend ratio of the constituent $\mathrm{MAPbI}_{3}$ perovskite, which could broaden the applications of the $\mathrm{PAN} / \mathrm{MAPbI}_{3}$ composite fibers in the semiconductor device field. 


\subsection{Photovoltaic Performance of the Composite Fibers}

Based on the obtained $\mathrm{PAN} / \mathrm{MAPbI}_{3}$ composite fibers, photodetectors were constructed on two pieces of glass substrates, as illustrated in Figure 6a. To examine the photoelectric properties of the composite fiber photodetectors, the photoresponses were characterized under simulated sunlight. For a conductive photodetector, the responsivity $(R)$ and external quantum efficiency $(E Q E)$ are the figures of merit to evaluate the performance of a different geometry device. $R$ and $E Q E$ are calculated by the following equations:

$$
\begin{aligned}
R= & \left(I_{\text {light }}-I_{\text {dark }}\right) / E_{\text {light }} \\
& E Q E=h c R / e \lambda
\end{aligned}
$$

where $I_{\text {light }}$ and $I_{\text {dark }}$ are the current under light and dark respectively, $E_{\text {light }}$ is the power of incident illumination, $h$ is the Planck constant, $c$ is the speed of light, $\lambda$ is the wavelength of the incident light, and $e$ is the unit charge.
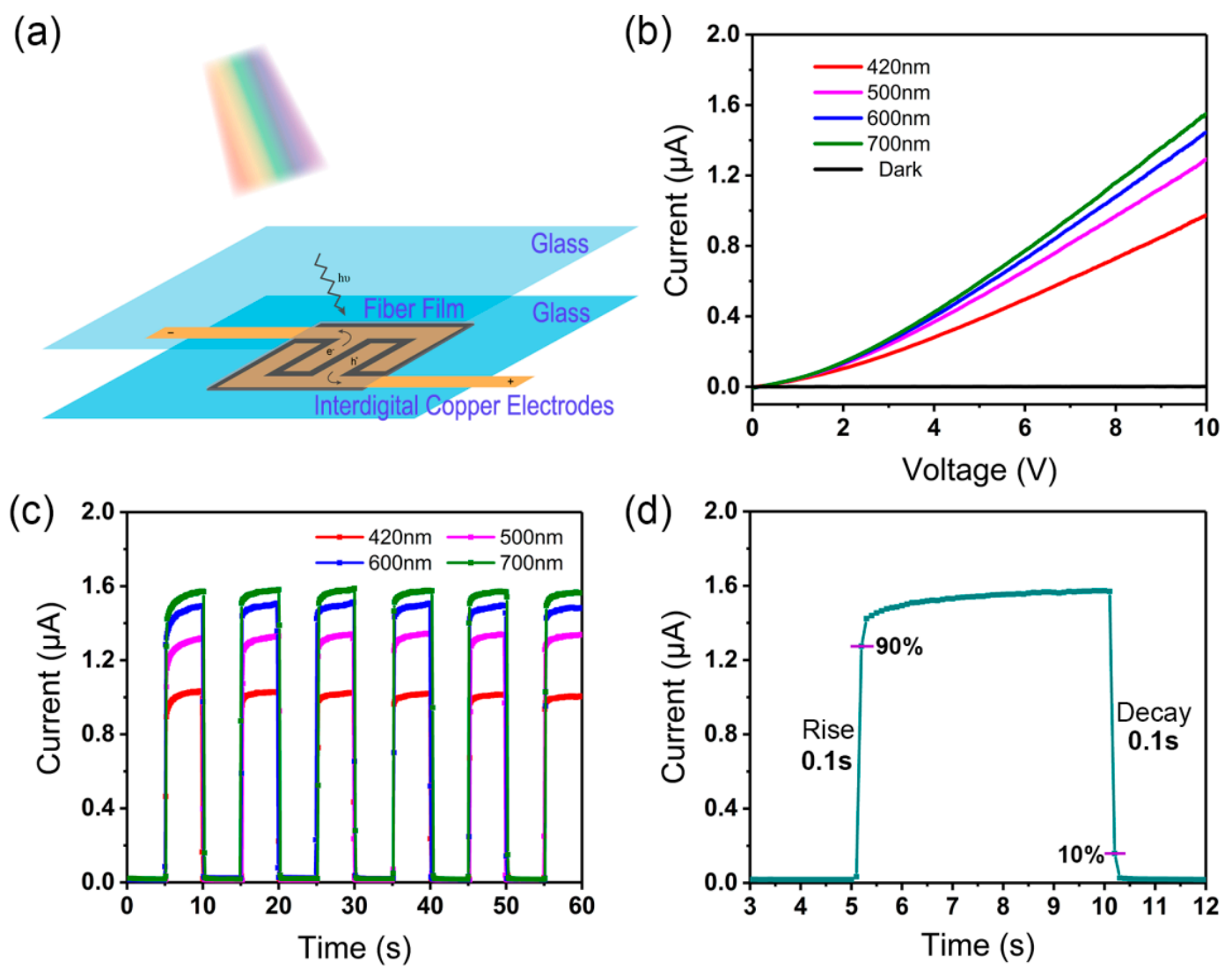

Figure 6. Photoresponse performance of the photodetectors. (a) Schematic illustration of the photodetector. (b) Current-voltage curve and (c) photocurrent responses of the detector based on the M85.7 fibers. (d) Transient response of the photodetector based on the M85.7 fibers.

The photoresponse was measured at different wavelengths, ranging from 420 to 500, 600, and $700 \mathrm{~nm}$ (Figure S3). As shown in Figure 6b, different photocurrent responses under different wavelengths were observed for the photodetector based on M85.7 composite fibers. Under the light illumination of $100 \mathrm{~mW} \mathrm{~cm}^{-2}$, the photocurrent of the device increased gradually from 1.0 to $1.5 \mu \mathrm{A}$, with an increase in the light wavelength from 420 to $700 \mathrm{~nm}$, which is attributed to an increase in the quantity of electrons excited. This is agreeable with other reported perovskite photodetectors [9-16]. The photoconduction is based on the electron-hole pairs, which are excited due to the incident light with energy larger than the band gap. The conductance of the device can be increased significantly with light illumination. Although a photon with larger energy in the shorter wavelength will excite 
more electrons [6], a beam of longer-wavelength light has more photons under the same light intensity $\left(100 \mathrm{~mW} \mathrm{~cm}^{-2}\right)$. Therefore, the transition probability increases for longer wavelengths at the same light intensity, resulting in a large increase in free-carrier density and easier carrier transport and injection, thus enhancing the photocurrent of the photoelectric devices greatly, which was reflected in the increase of the photocurrent $(1.5 \mu \mathrm{A})$.

The photoresponse was measured as a function of time during repetitive switching of different-wavelength light illumination at a bias of $10 \mathrm{~V}$, as shown in Figure 6c. The saturated photocurrent increased with increasing of the light wavelength from 420 to $700 \mathrm{~nm}$, which is consistent with the current-voltage $(\mathrm{CV})$ curve results. For the M85.7 composite fiber, the responsivity $R$ reached $6.5 \mu \mathrm{A} \mathrm{W}^{-1}$ at $700 \mathrm{~nm}$, with an extremely low EQE (0.002\%). The EQE of these photodetectors is poor, mainly because the carrier diffusion length is much shorter than the distance between two neighboring fingers $(0.75 \mathrm{~mm})$. Consequently, a large number of pairs vanished because of the enhanced charge recombination [29]. The composite fiber photodetector could be rapidly and reversibly switched on and off, periodically at approximately 5-s intervals. When the Xenon lamp was switched on, a fast-transient current could be observed. In addition, the undeniable role of the quality of the composite fibers is also indicated by the time dependence of the photocurrent. As shown in Figure $6 \mathrm{~d}$, the rise time was measured as the transition time between the minimum current to $90 \%$ of the maximum value, and the fall time was defined from the maximum value down to 10\%. For the M85.7 photodetector, the characteristic rise and fall times were both approaching $0.1 \mathrm{~s}$. It is reasonable to suppose that an increase in $\mathrm{MAPbI}_{3}$ perovskite content could increase the responsivity.

The content of perovskite plays a critical role in the performance of the photodetectors, as shown in Figure 7a. The M85.7 photodetector had the strongest photocurrent response under the same conditions, due to its higher perovskite content. The on/off current ratio of the M85.7 photodetector could achieve around 100 at $420 \mathrm{~nm}$, and 80 at $700 \mathrm{~nm}$ at a bias of $10 \mathrm{~V}$. The dark current was only $10^{-8}$ A. However, the M77.7 photodetector could only achieve an on/off current ratio of 23 at $700 \mathrm{~nm}$.
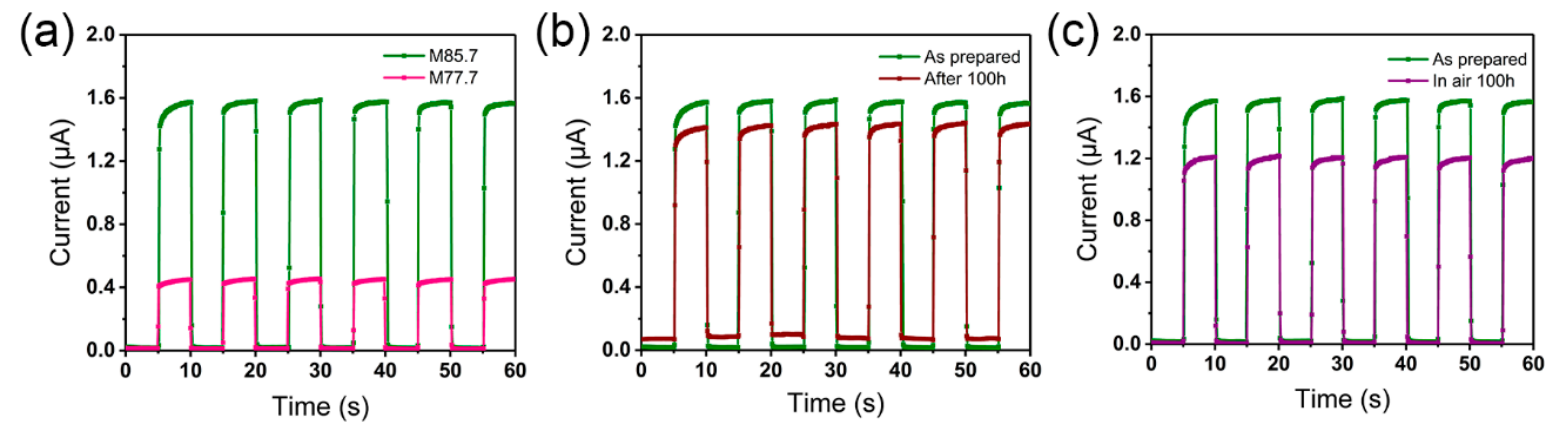

Figure 7. Photoresponse performance of the photodetectors. (a) Comparison of photocurrent between M77.7 and M85.7 at $700 \mathrm{~nm}$. (b) M85.7 device retained over $85 \%$ of its initial responsivity after $100 \mathrm{~h}$ exposure to moisture. (c) M85.7 device retained nearly 75\% of its initial responsivity after fibers were exposed to ambient air for $100 \mathrm{~h}$.

Upon Xenon lamp illumination, plenty of electron-hole pairs can be generated in the hybrid perovskite, and excellent contact can be formed between the copper electrodes and the composite fibers. Therefore, the higher the perovskite content in the composite fibers, the stronger the photocurrent of the photodetectors. The low $I_{\text {dark }}$ indicates an impressively low free-carrier density. The migration of electrons and holes is inhibited because of the high-contact barrier at the interface of $\mathrm{Cu} /$ perovskite in the dark. Therefore, the photodetectors can reach a high photo-to-dark current ratio at $10 \mathrm{~V}$, indicating that the composite fibers are suitable for practical photon-detection applications.

All these results demonstrate that $\mathrm{PAN} / \mathrm{MAPbI}_{3}$ composite fibers can be used in fast photoelectric switches and highly sensitive photodetectors. Compared to other $\mathrm{MAPbI}_{3}$ fiber photodetectors, which have been reported to be unstable in the majority of ordinary solvents and the air environment, 
the composite perovskite fiber photodetectors not only show remarkable responses, but also have much better stability.

As shown in Figure 7b, the stability and photoresponses of the composite fiber photodetectors were studied after $100 \mathrm{~h}$ exposure to moisture. The devices retained over $85 \%$ of their initial responsivity, without deterioration of the key photoelectric properties. This suggests that the polymer may act as a protection buffer between $\mathrm{MAPbI}_{3}$ and atmospheric moisture, elongating the lifetime of the photodetectors in ambient air. Predictably, M66.6 and M77.7 have better stability because of their higher content of PAN. M85.7 composite fibers were placed in air firstly for $100 \mathrm{~h}$, and then used to fabricate photodetectors. Nearly $75 \%$ of their initial responsivity was retained, as shown in Figure 7c. Their reduced stability was due to the lack of the protection of glass encapsulation when exposed to air, indicating that glass encapsulation is another important factor that influences the stability.

As shown in Figure 8a-c, these photodetectors also exhibit impressive photoresponses under various conditions (laser, flashlight, and fluorescent lamp), and maintain their performance after $100 \mathrm{~h}$ exposure in air.
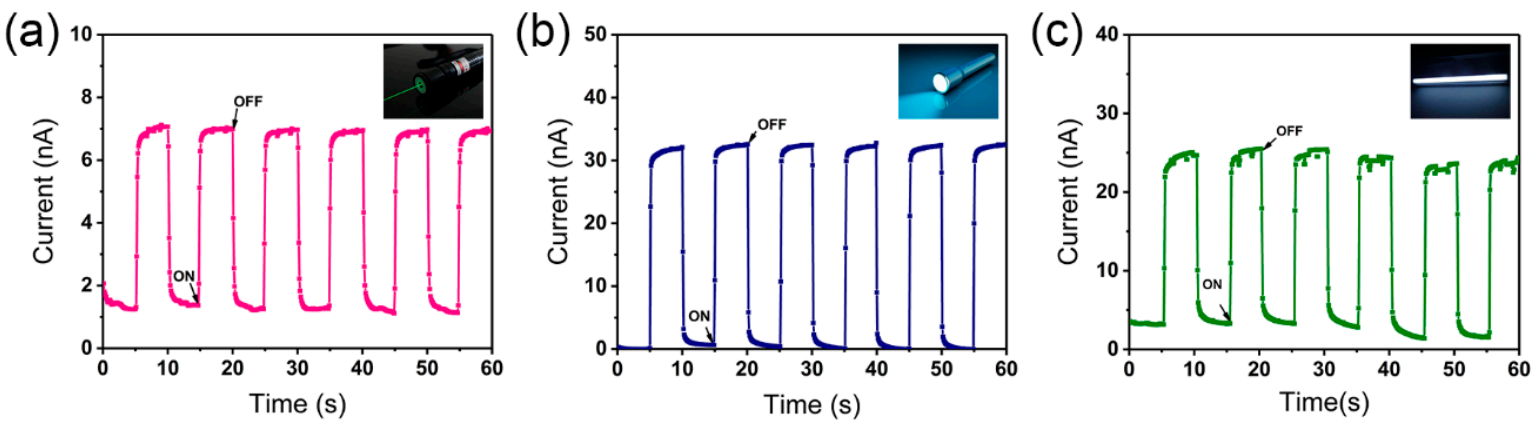

Figure 8. Photoresponse performance under different light sources. (a) Laser, (b) flashlight, and (c) fluorescent lamp.

\subsection{Thermal Stability of the Composite Fibers}

The thermal stability is also an important figure of merit to evaluate the application of the composite fibers. TGA measurements were carried out with a heating rate of $20^{\circ} \mathrm{C} / \mathrm{min}$ under $\mathrm{N}_{2}$ atmosphere, and the results are shown in Figure $9 . \mathrm{MAPbI}_{3}$ is generally thermally stable up to $300{ }^{\circ} \mathrm{C}$ [4]. The M85.7 composite fibers start losing slight weight at $160^{\circ} \mathrm{C}$. The curve indicates that the thermal decomposition of the as-spun fibers is completed in three distinct steps. In the first step, the weight loss is observed between 160 and $300^{\circ} \mathrm{C}$, which may be due to the evaporation of DMF. In the second and third steps (300-400 and $>400{ }^{\circ} \mathrm{C}$ ), the weight loss of approximately $70 \mathrm{wt} \%$ is due to the degradation of $\mathrm{MAPbI}_{3}$ and $\mathrm{PAN}$. The composite fibers are thermally stable and fully meet the design and work requirements of the photoelectric devices.

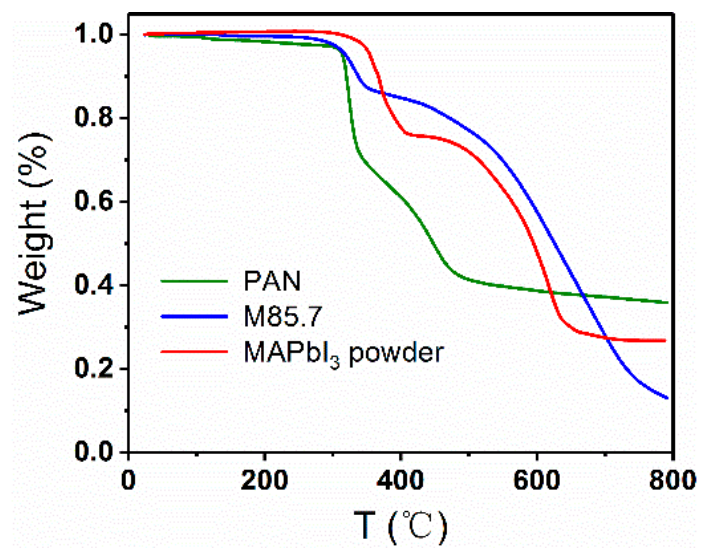

Figure 9. TGA curves of the M85.7 fibers, $\mathrm{PAN}$ fibers, and pure $\mathrm{MAPbI}_{3}$ powder. 


\subsection{Motion Detections of the Flexible Photodetectors}

Flexible photodetectors were also constructed through replacing glass substrate with flexible polyethylene terephthalate (PET), which was then coated with silver electrodes. To examine the relationship between photocurrent and flexibility of the photodetectors, the photoresponse was characterized under different bending angles, as shown in Figure 10. As the bending degree decreased, the photocurrent became stronger. The flexible photodetector showed the strongest photocurrent response without bending. This result demonstrates that bending angles play a critical role in the photocurrent of the flexible photodetectors. Therefore, this flexible detector may be used to detect motion-related angular changes (Figure 10f).
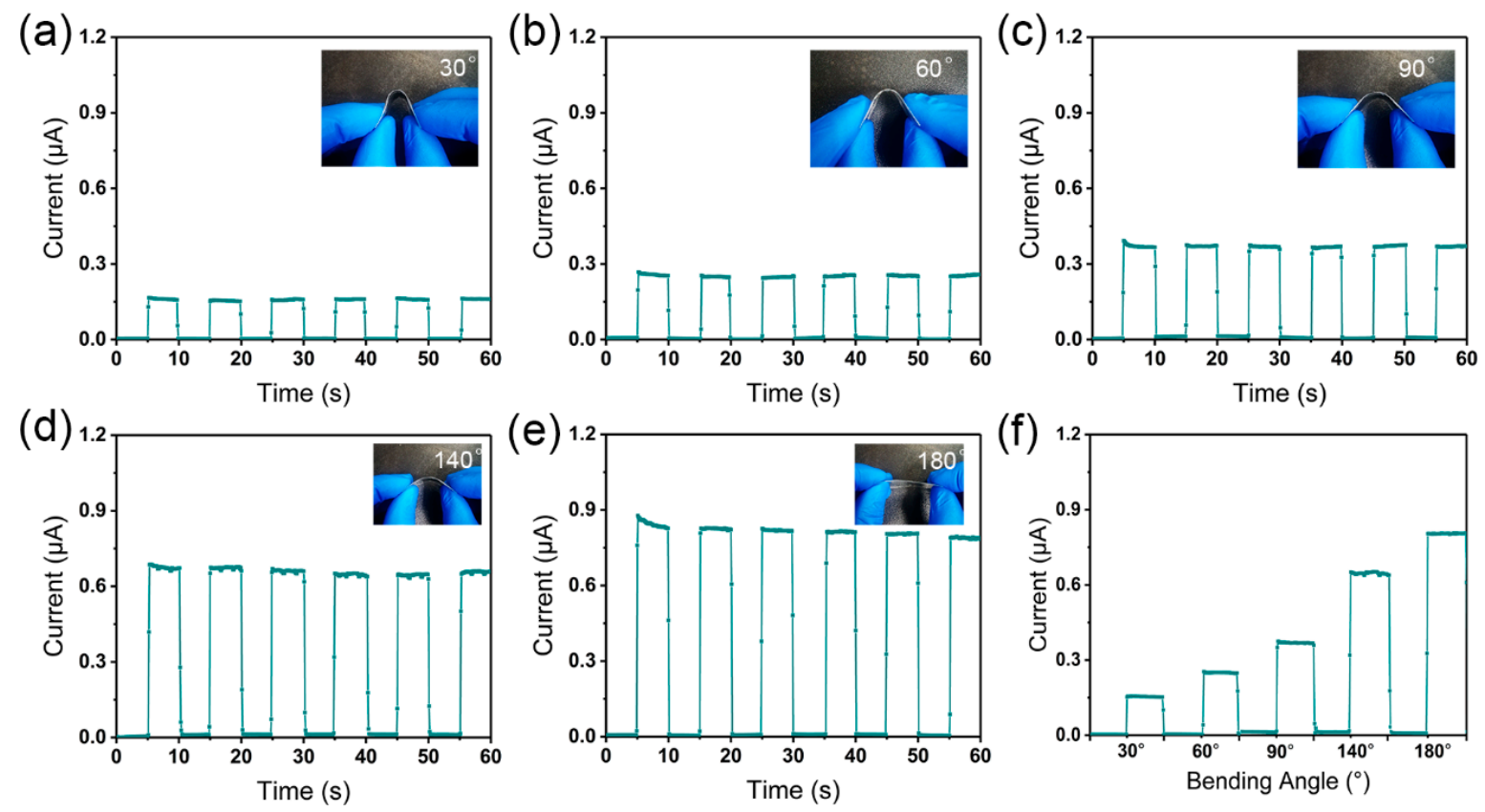

Figure 10. Motion detections of the flexible photodetectors. (a-e) Photocurrent of flexible composite fiber photodetectors under different bending angles. (f) Relationship between photocurrent and bending angles.

\section{Conclusions}

In summary, electrospun $\mathrm{PAN} / \mathrm{MAPbI}_{3}$ perovskite fibers were successfully fabricated, and broadband photodetectors were constructed from the obtained composite fibers. $\mathrm{MAPbI}_{3}$ perovskite nanocrystals were detected in the composite fibers, which have much-improved stability due to the protection of PAN polymers. It is also possible to adjust the absorption edge or the bandgap of the composite fibers by controlling the content of $\mathrm{MAPbI}_{3}$. The photodetectors have high sensitivity, rapid photoresponses, and improved stability. The flexible photodetectors based on the obtained M85.7 composite fibers show different photocurrent responses at different bending angles. These studies suggest that a simple fabrication of perovskite/polymer composite fibers by electrospinning can broaden the applications of perovskite in the optoelectronic fields, and inspire the development and application of different polymer/perovskite composite systems. Our strategy may pave the way towards polymer/perovskite composite fibers suitable for various flexible photoelectronic devices.

Supplementary Materials: The following are available online at http:/ / www.mdpi.com/2079-4991/9/1/50/s1, Figure S1: SEM images of polyacrylonitrile (PAN) fibers, Figure S2: SEM cross-section images of the composite fibers, Figure S3: Transmission of different wavelength filters.

Author Contributions: Z.C. and Z.J. conceived the topic and supervised the experimental work. G.L. and W.W. carried out Methodology, Validation, and Formal Analysis. G.L., Y.Z., Z.C., and C.W. outlined the manuscript and mainly wrote it. All the authors contributed to the discussion and reviewed the manuscript. 
Funding: The research was financially supported by National Natural Science Foundation of China (61574172), and Research Program of National University of Defense Technology (ZK16-03-47).

Conflicts of Interest: The authors declare no conflict of interest.

\section{References}

1. Kojima, A.; Teshima, K.; Shirai, Y.; Miyasaka, T. Organometal Halide Perovskites as Visible-Light Sensitizers for Photovoltaic Cells. J. Am. Chem. Soc. 2009, 131, 6050-6051. [CrossRef]

2. Dong, Q.; Fang, Y.; Shao, Y.; Mulligan, P.; Qiu, J.; Cao, L.; Huang, J. Electron-hole diffusion lengths > $175 \mu \mathrm{m}$ in solution-grown $\mathrm{CH}_{3} \mathrm{NH}_{3} \mathrm{PbI}_{3}$ single crystals. Science 2015, 347, 967-970. [CrossRef] [PubMed]

3. Liu, Y.; Yang, Z.; Cui, D.; Ren, X.; Sun, J.; Liu, X.; Zhang, J.; Wei, Q.; Fan, H.; Yu, F.; et al. Two-Inch-Sized Perovskite $\mathrm{CH}_{3} \mathrm{NH}_{3} \mathrm{PbX}_{3}(\mathrm{X}=\mathrm{Cl}, \mathrm{Br}, \mathrm{I})$ Crystals: Growth and Characterization. Adv. Mater. 2015, 27, 5176-5183. [CrossRef] [PubMed]

4. Dang, Y.; Liu, Y.; Sun, Y.; Yuan, D.; Liu, X.; Lu, W.; Liu, G.; Xia, H.; Tao, X. Bulk Crystal Growth of Hybrid Perovskite Material $\mathrm{CH}_{3} \mathrm{NH}_{3} \mathrm{PbI}_{3}$. CrystEngComm 2015, 17, 665-670. [CrossRef]

5. Gao, L.; Zeng, K.; Guo, J.; Ge, C.; Du, J.; Zhao, Y.; Chen, C.; Deng, H.; He, Y.; Song, H.; et al. Passivated Single-Crystalline $\mathrm{CH}_{3} \mathrm{NH}_{3} \mathrm{PbI}_{3}$ Nanowire Photodetector with High Detectivity and Polarization Sensitivity. Nano Lett. 2016, 16, 7446-7454. [CrossRef]

6. Hu, X.; Zhang, X.; Liang, L.; Bao, J.; Li, S.; Yang, W.; Xie, Y. High-Performance Flexible Broadband Photodetector Based on Organolead Halide Perovskite. Adv. Funct. Mater. 2014, 24, 7373-7380. [CrossRef]

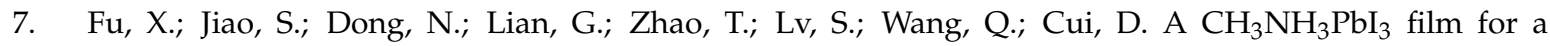
room-temperature $\mathrm{NO}_{2}$ gas sensor with quick response and high selectivity. RSC Adv. 2018, 8, 390-395. [CrossRef]

8. Tong, S.; Wu, H.; Zhang, C.; Li, S.; Wang, C.; Shen, J.; Xiao, S.; He, J.; Yang, J.; Sun, J.; et al. Large-Area and High-Performance $\mathrm{CH}_{3} \mathrm{NH}_{3} \mathrm{PbI}_{3}$ Perovskite Photodetectors Fabricated via Doctor Blading in Ambient Condition. Org. Electron. 2017, 49, 347-354. [CrossRef]

9. Hu, W.; Huang, W.; Yang, S.; Wang, X.; Jiang, Z.; Zhu, X.; Zhou, H.; Liu, H.; Zhang, Q.; Zhuang, X.; et al. High-Performance Flexible Photodetectors based on High-Quality Perovskite Thin Films by a Vapor-Solution Method. Adv. Mater. 2017, 29, 1703256. [CrossRef] [PubMed]

10. Chen, S.; Teng, C.; Zhang, M.; Li, Y.; Xie, D.; Shi, G. A Flexible UV-Vis-NIR Photodetector based on a Perovskite/Conjugated-Polymer Composite. Adv. Mater. 2016, 28, 5969-5974. [CrossRef]

11. Hu, H.; Yan, K.; Peng, M.; Yu, X.; Chen, S.; Chen, B.; Dong, B.; Gao, X.; Zou, D. Fiber-shaped perovskite solar cells with 5.3\% efficiency. J. Mater. Chem. A 2016, 4, 3901-3906. [CrossRef]

12. Im, J.H.; Luo, J.; Franckevicius, M.; Pellet, N.; Gao, P.; Moehl, T.; Zakeeruddin, S.M.; Nazeeruddin, M.K.; Gratzel, M.; Park, N.G. Nanowire perovskite solar cell. Nano Lett. 2015, 15, 2120-2126. [CrossRef] [PubMed]

13. Horváth, E.; Spina, M.; Szekrényes, Z.; Kamarás, K.; Gaal, R.; Gachet, D.; Forró, L. Nanowires of Methylammonium Lead Iodide $\left(\mathrm{CH}_{3} \mathrm{NH}_{3} \mathrm{PbI}_{3}\right)$ Prepared by Low Temperature Solution-Mediated Crystallization. Nano Lett. 2014, 14, 6761-6766. [CrossRef] [PubMed]

14. Zhu, H.; Fu, Y.; Meng, F.; Wu, X.; Gong, Z.; Ding, Q.; Gustafsson, M.V.; Trinh, M.T.; Jin, S.; Zhu, X.Y. Lead halide perovskite nanowire lasers with low lasing thresholds and high quality factors. Nat. Mater. 2015, 14, 636. [CrossRef] [PubMed]

15. Hu, Q.; Wu, H.; Sun, J.; Yan, D.; Gao, Y.; Yang, J. Large-area perovskite nanowire arrays fabricated by large-scale roll-to-roll micro-gravure printing and doctor blading. Nanoscale 2016, 8, 5350-5357. [CrossRef] [PubMed]

16. Deng, H.; Dong, D.; Qiao, K.; Bu, L.; Li, B.; Yang, D.; Wang, H.-E.; Cheng, Y.; Zhao, Z.; Tang, J.; et al. Growth, patterning and alignment of organolead iodide perovskite nanowires for optoelectronic devices. Nanoscale 2015, 7, 4163-4170. [CrossRef] [PubMed]

17. Zhu, C.; Tang, Y.; Chen, F.; Manohari, A.G.; Zhu, Y.; Shi, Z.; Xu, C. Fabrication of self-assembly polycrystalline perovskite microwires and photodetectors. J. Cryst. Growth 2016, 454, 121-127. [CrossRef]

18. Chao, L.M.; Tai, T.Y.; Chen, Y.Y.; Lin, P.Y.; Fu, Y.S. Fabrication of $\mathrm{CH}_{3} \mathrm{NH}_{3} \mathrm{PbI}_{3} / \mathrm{PVP}$ Composite Fibers via Electrospinning and Deposition. Materials 2015, 8, 5467-5478. [CrossRef] [PubMed]

19. Spina, M.; Bonvin, E.; Sienkiewicz, A.; Náfrádi, B.; Forró, L.; Horváth, E. Controlled growth of $\mathrm{CH}_{3} \mathrm{NH}_{3} \mathrm{PbI}_{3}$ nanowires in arrays of open nanofluidic channels. Sci. Rep. 2016, 6, 19834. [CrossRef] [PubMed] 
20. Leguy, A.M.A.; Hu, Y.; Campoy-Quiles, M.; Alonso, M.I.; Weber, O.J.; Azarhoosh, P.; van Schilfgaarde, M.; Weller, M.T.; Bein, T.; Nelson, J.; et al. Reversible Hydration of $\mathrm{CH}_{3} \mathrm{NH}_{3} \mathrm{PbI}_{3}$ in Films, Single Crystals, and Solar Cells. Chem. Mater. 2015, 27, 3397-3407. [CrossRef]

21. Smith, I.C.; Hoke, E.T.; Solis-Ibarra, D.; McGehee, M.D.; Karunadasa, H.I. A Layered Hybrid Perovskite Solar-Cell Absorber with Enhanced Moisture Stability. Angew. Chem. Int. Ed. 2014, 53, 11232-11235. [CrossRef] [PubMed]

22. Aristidou, N.; Eames, C.; Islam, M.S.; Haque, S.A. Insights into the increased degradation rate of $\mathrm{CH}_{3} \mathrm{NH}_{3} \mathrm{PbI}_{3}$ solar cells in combined water and $\mathrm{O}_{2}$ environments. J. Mater. Chem. A 2017, 5, 25469-25475. [CrossRef]

23. Hildebrandt, N.C.; Soldat, J.; Marschall, R. Layered Perovskite Nanofibers via Electrospinning for Overall Water Splitting. Small 2015, 11, 2051-2057. [CrossRef] [PubMed]

24. Murphy, J.P.; Ross, B.M.; Andriolo, J.M.; Skinner, J.L. Hybrid Organic-Inorganic Perovskite Composite Fibers Produced via Melt Electrospinning. J. Vac. Sci. Technol. B 2016, 34, 06KM01. [CrossRef]

25. Zeng, X.L.; Koblischka, M.R.; Karwoth, T.; Hauet, T.; Hartmann, U. Preparation of Granular Bi-2212 Nanowires by Electrospinning. Supercond. Sci. Technol. 2017, 30, 035014. [CrossRef]

26. Lu, J.; Zhang, L.; Peng, C.; Rao, L.; Wan, M. Preparation and Characterization of $\mathrm{CH}_{3} \mathrm{NH}_{3} \mathrm{PbI}_{3}$ Perovskite Deposited onto Polyacrylonitrile (PAN) Nanofiber Substrates. Chem. Lett. 2016, 45, 312-314. [CrossRef]

27. Chen, D.; Zhu, Y. Electrospun Perovskite Nanofibers. Nanoscale Res. Lett. 2017, 12, 114. [CrossRef]

28. Baikie, T.; Fang, Y.; Kadro, J.M.; Schreyer, M.; Wei, F.; Mhaisalkar, S.G.; Graetzel, M.; White, T.J. Synthesis and crystal chemistry of the hybrid perovskite $\left(\mathrm{CH}_{3} \mathrm{NH}_{3}\right) \mathrm{PbI}_{3}$ for solid-state sensitised solar cell applications. J. Mater. Chem. A 2013, 1,5628-5641. [CrossRef]

29. Wang, X.; Song, W.; Liu, B.; Chen, G.; Chen, D.; Zhou, C.; Shen, G. High-Performance Organic-Inorganic Hybrid Photodetectors Based on $\mathrm{P}_{3} \mathrm{HT}$ : CdSe Nanowire Heterojunctions on Rigid and Flexible Substrates. Adv. Funct. Mater. 2013, 23, 1202-1209. [CrossRef]

(C) 2019 by the authors. Licensee MDPI, Basel, Switzerland. This article is an open access article distributed under the terms and conditions of the Creative Commons Attribution (CC BY) license (http:/ / creativecommons.org/licenses/by/4.0/). 